\title{
Elementos para uma política cultural pós-individualista ${ }^{1}$
}

\author{
Notes for a post-individualistic cultural politics
}

\section{Aldir Araújo Carvalho Filho}

UFMA

Resumo: Este texto apresenta alguns elementos básicos de reflexão para favorecer mudanças no paradigma cultural dominante: o individualismo. Retomando a metáfora rortyana do "declínio da verdade redentora e da ascensão de uma cultura literária", tento mostrar que se a literatura é eficaz na ampliação da sensibilidade, algo necessário à construção de uma cultura pós-individualista, ela não pode ser identificada tout court, como quer Rorty, ao ideal liberal da mera autocriação privada.

Palavras-Chave: (Pós-)Individualismo, Neo-pragmatismo, Richard Rorty, Política Cultural, Autocriação Privada.

Abstract: This paper presents some basic elements of reflection in order to favour shifting in the dominant cultural paradigm: individualism. By reassessing Rorty's metaphor of the "decline of a redemptive truth and the ascension of a literary culture", I try to argue that if literature is effective in enhancing sensitivity, something necessary to the construction of a post-individualistic culture, it cannot be tout court identified, as Rorty wants, to the liberal ideal of mere private self-creation.

Key-Words: (Post-)Individualism, Neo-pragmatism, Richard Rorty, Cultural Politics, Private Self-Creation.

Se tudo faço no interesse de minha pessoa é porque o interesse que deposito em minha pessoa tudo precede. (Sêneca)

De acordo com Richard Rorty, o papel dos intelectuais é efetuar mudanças culturais explicando como novas ideias poderiam, se fossem experimentadas, resolver, ou desfazer, os problemas criados pelas antigas (Rorty, 2009, p. 149). Como sabem, o contexto no qual esta ideia de Rorty se justifica é o seu esforço em propiciar o reconhecimento, por parte da maioria ainda renitente dos intelectuais, de uma

\footnotetext{
${ }^{1}$ Texto original da Conferência de Abertura da $1^{\text {ạ }}$ Jornada de Pesquisa do Mestrado em Ética e Epistemologia, ministrada em dezembro de 2009, na Universidade Federal do Piauí. 
mudança de paradigma cultural que, segundo ele, já está em curso na cultura desde Cervantes e Shakespeare, e que na filosofia se entronizou desde Hegel: trata-se do declínio da "verdade redentora" e da ascensão de uma "cultura literária". Para Rorty, a principal experiência que conviria fazer provar aos intelectuais seria o entendimento de sua própria atividade como um gênero literário contingente e particular que serve aos interesses do momento e às necessidades humanas históricas, e não como o lugar da profecia, da revelação ou do oráculo da Verdade e da Ciência.

Estou plenamente de acordo com Rorty quanto ao papel contemporâneo dos intelectuais, mormente dos que se ocupam com o gênero literário filosófico. Todavia, não o acompanho nos motivos de fundo que o levam a valorizar tanto essa mudança já em andamento. De fato, a mudança cultural que me interessa deflagrar, e a única que julgo fazer sentido para a minha própria atividade intelectual, é de orientação bastante diversa da que serve de inspiração a Rorty. Reputo que a mais importante mudança cultural de que necessitamos é o abandono completo da linha mestra do código cultural dominante atual, e que embora não esteja em relação de dependência ou influência direta do advento da cultura literária, certamente se tornou muito mais sofisticado com o seu triunfo.

Refiro-me à ideia individualista ou, simplesmente, o individualismo. Defino individualismo como a exacerbação idiótica da individualidade dos indivíduos humanos (Carvalho Filho, p. 30). Trata-se de um "defeito genético" no código cultural moderno e, de fato, seu elemento determinante. De acordo com Louis Dumont, é a ideologia central no Ocidente a partir da Era Moderna, embora venha sendo construída desde muito antes disso. Esse paradigma dominante é responsável pela maior parte dos nossos problemas, a começar por nossa organização política, cuja dificuldade central, hoje, poderia ser resumida do seguinte modo: como garantir todos os direitos individuais a todos os indivíduos, quando sabemos que as instituições políticas modernas, mesmo aquelas do Estado de Bem Estar Social, fazem valer a primazia da pessoa moral sobre a coletividade, o que significa dizer que as desigualdades econômicas e sociais estão garantidas de tal modo que é impossível que todos tenham 
os seus direitos igualmente atendidos. Assim, nossa vida humana, pela ideologia individualista, é uma loteria em que apenas os mais afortunados podem ter alguma chance.

Ora, é claro que não podemos concordar com isso, nós que sabemos que as situações humanas, sobretudo as que definem ordens políticas, são resultados de soluções e convenções contingentes e mutáveis e que não contam, no mais essencial, com qualquer intervenção de ordem extra-humana, exceto os infortúnios ocasionais das doenças e dos cataclismos naturais.

Pois bem, essa ordem individualista tem dado aos indivíduos modernos uma coleção de problemas que não parecem refluir, mas, ao contrário, se ampliam com a instalação cada vez mais sólida dos arranjos políticos dominantes, isto é, com a expansão globalizada do par liberalismo/capitalismo. Essa crise que vivemos tem gerado efeitos extremamente deletérios sobre os indivíduos, considerados individualmente. Em particular, se destacariam:

a) A exclusão sócio-econômica (Baumann);

b) A sobrecarga psíquica e existencial que resulta das dificuldades de construção social da própria identidade em meio à pluralidade socialmente desreferenciada dos valores e à fragmentação cultural (Geertz);

c) A angústia de manutenção da própria sobrevivência, mesmo para os trabalhadores com alto nível de formação, provocada pela alteração globalizada nas relações entre capital e trabalho e pela incerteza sobre os movimentos especulativos da economia capitalista (Barbosa);

d) A anomia, o narcisismo e a atomização, característicos da vida nos grandes centros urbanos (Sodré) (como se sabe, em Londres e Paris, por exemplo, quase $60 \%$ das habitações são ocupadas por apenas um morador);

e) E, por último, a constante sensação de abandono, responsável pelo incremento na percepção individual de infelicidade (Kuperman). 
Com a "racionalização" intrínseca à modernização industrial e, mais recentemente, com o advento da era digital, em que os fluxos financeiros são movimentados diuturnamente em escala global, todos esses problemas adquiriram uma tonalidade ainda mais dramática. E infelizmente, pace Rorty, o triunfo cultural da literatura, por enquanto, só pode tornar as características ideológicas do individualismo ainda mais refinadas e aguçadas, na medida em que seu principal foco tem sido a promoção sistemática do direito à autocriação imaginária individual como rumo de saída coletivo. Ou seja, mais do que nunca a palavra de ordem na cultura literária é um "cuidado de si" retomado de forma pasteurizada (Foucault). Na prática da nossa vida econômica cotidiana, eu traduziria esse mote pelo lema mais chulo, mas bastante realista, do "salve-se quem puder".

Apesar disso, levo muito a sério a ideia rortyana de que quando as tradições culturais começam a fazer as pessoas desnecessariamente miseráveis, essas tradições estão a nos dizer que sua sobrevivência é completamente inútil e que elas precisam ser substituídas por outras tradições culturais. Entendo que se um código cultural pósindividualista se tornasse dominante poderíamos, enfim, resolver os inúmeros problemas que hoje nos afligem.

E é nesse espírito que gostaria de apresentar aqui alguns elementos que julgo poderem servir para auxiliar a efetuar mudanças culturais na direção de um paradigma pós-individualista. A rigor, não estou em condições de oferecer um novo vocabulário para começar a substituir aqueles de matriz individualista que normalmente usamos, e que são muito freqüentes, sobretudo nas tradições filosóficas de modo geral. São esses os vocabulários pelos quais nos reproduzimos e com os quais vimos perpetuando nossos principais problemas. Contudo, posso tentar apresentar algumas considerações e introduzir elementos de crítica e de reflexão (dois exemplos de vocabulário individualista) sobre os vocabulários atuais, elementos que talvez nos ajudem a nos sentir cada vez mais desconfortáveis com isso que ainda utilizamos e que, assim, possam nos estimular a construir metáforas pós-individualistas, mais úteis para nós mesmos e para os outros, ainda que eles não vejam imediatamente a sua utilidade 
como nós a vemos. De fato, essa mudança cultural que proponho pode inclusive se beneficiar das redescrições rortyanas sobre a ascensão da cultura literária, desde que se sirva do que interessa e que deixe de lado o que não ajuda.

Em resumo, qual seria a síntese principal dos vocabulários individualistas que hoje ainda utilizamos? Diria que é a idéia da subjetividade como liberdade, pela qual o indivíduo moderno sabe de si mesmo, deseja a si mesmo e cuida de si mesmo como o mais sacrossanto de todos os princípios. Garantido o respeito a esse princípio, tudo o mais é possível, tal como o anuncia a epígrafe de Sêneca que utilizei para esse texto, e todas as coisas podem ser permitidas, tanto as maiores injustiças quanto os maiores absurdos emocionais, pessoais, legais, econômicos, etc. Então, seria importante, antes de tudo o mais, recapitularmos muito brevemente o histórico do desenvolvimento desse princípio na cultura.

A sociologia comparada de Dumont nos ensina que, há quase cinco mil anos, na sociedade indiana tem predominado uma ideologia hierárquico-holista, em que ocorre uma interdependência obrigatória para os indivíduos por meio de um conjunto de relações sociais. Contudo, no interior dessa ideologia dominante, subsiste a figura da independência do indivíduo mediante a escolha da via da renúncia, uma instituição indiana ancorada, como quase tudo mais, nos textos sagrados antigos (Dumont, 1992, p. 35).

O renunciante indiano basta-se a si próprio, não se preocupa senão consigo mesmo. Seria idêntico ao indivíduo moderno, exceto pelo fato de que o renunciante vive fora do mundo social, permitindo a Dumont chamar esse tipo de indivíduo pela fórmula "indivíduo-fora-do-mundo". Baseando-se nos textos sagrados indianos, o renunciante é o indivíduo que se dispõe a "procurar a verdade última", o que busca a "redenção" ou a "salvação", e por isso abandona a vida social com suas preocupações e imposições. Para ele, a salvação só pode vir se primeiro houver uma libertação dos entraves da vida compartilhada. O curioso, contudo, é que mesmo podendo viver como eremita, o renunciante solitário geralmente se junta - talvez numa necessidade inconfessa de convívio social - a outros renunciantes, sob a direção de um "mestre- 
renunciante" (Idem, p. 36). Mas, mesmo em comunidade religiosa, esse indivíduo não abre mão do distanciamento relativamente ao mundo social, como condição de seu desenvolvimento espiritual.

Dumont afirma ainda que a mesma categoria sociológica do indivíduo-fora-domundo está presente no Cristianismo primitivo. E pertence também, inegavelmente, ao ambiente cultural helenístico das escolas pós-socráticas que cercam o florescimento e a consolidação dessa nova religião. Já Foucault, em seus cursos do Collége de France de 1982, nos havia ensinado o quanto a idéia do "cuidado de si" foi recalcada por uma interpretação equivocada do "conhece-te a ti mesmo", a ordem do deus para Sócrates. Esse recalque mostra uma dinâmica histórica em que o conhecimento da verdade revelada do cristianismo acabou por suplantar o conhecimento construído pela busca de sabedoria e imersão na própria reflexão, característica do período socrático. Assim, em vez de uma ocupação com "o mundo social", tal como Platão e Aristóteles o prescrevem, o cristianismo acabou, com as escolas pós-socráticas, por impor uma ética de tipo individualista, mesmo que seja um “individualismo-no-mundo". De toda maneira, o que é importante para Foucault é mostrar que essa idéia do cuidado de si foi sistematicamente retomada pelas escolas pós-socráticas e que, de algum modo, juntamente com as categorias platônicas e neoplatônicas, foi responsável pelo aparelhamento vocabular do cristianismo incipiente, ainda que vertido como "salvação de si".

O que importa mostrar é que qualquer tentativa de adaptação ao mundo, seja no período helenístico, seja com o cristianismo primitivo é obtida por meio da relativização dos valores mundanos, exatamente do mesmo modo como ocorre com os renunciantes indianos. No estoicismo, por exemplo, isso se conseguia pelo estabelecimento de uma dicotomia radical entre a sabedoria e o mundo, entre os sábios, renunciantes, e os homens não esclarecidos (aqueles que "não são nós"), que continuam a ser presas da vida mundana (Dumont, 1992, p. 37).

E é essa atmosfera intelectual a responsável pela difusão universal da mensagem cristã. É que o cristão é um "indivíduo-em-relação-com-Deus”, isto é, um 
"indivíduo-no-mundo", mas orientado pelo "fora-do-mundo", vale dizer, alguém que se vê de modo claramente individualista, em oposição a tudo o que "o mundo", "as preocupações sociais, as obrigações, etc." significa. Por meio de sua filiação divina, o indivíduo adquire um "valor infinito", ao mesmo tempo em que rebaixa e desvaloriza o mundo tal como é.

Também Platão tentou manter a oposição entre verdade e aparência como oposição entre a alma e o corpo, a sabedoria e a opinião. Mas, para ele, o papel do sábio não é o de abdicar da vida política, senão o de tornar-se o próprio centro dessa vida, como governante. O sábio é quem deve reinar na polis e, portanto, nela deve permanecer por uma questão de justiça cósmica. Mas ainda que a maior influência na organização e hierarquização categorial das doutrinas cristãs em seus primórdios esteja na herança platônica, por meio de Plotino, a ferramenta intelectual que permitiu ao Cristianismo pensar as instituições terrenas a partir da verdade extramundana não foi tanto a de "justiça cósmica" platônica. Essa ferramenta foi a ideia de uma lei da natureza tal como foi desenvolvida na ética dos estóicos. Eis o que diz Ernest Troeltsch:

\begin{abstract}
A idéia mestra é a idéia de Deus como Lei da Natureza universal, espirituale-física, que reina uniformemente sobre todas as coisas e como lei universal do mundo ordena a natureza, produz as diferentes posições do indivíduo na natureza e na sociedade, e transforma-se no homem em lei da razão, a qual reconhece Deus e é deste modo uma com ele... A Lei da Natureza exige assim, por um lado, a submissão ao curso harmonioso da natureza e ao papel atribuído a cada um no sistema social, e por outro, a elevação interior acima de tudo isso, a liberdade ético-religiosa e a dignidade da razão que, sendo uma com Deus, não poderá ser perturbada por qualquer acontecimento exterior ou sensível (Troeltsch apud Dumont, 1992, p. 43).
\end{abstract}

Vê-se, portanto, que é por meio de uma doutrina voltada para a configuração de uma moralidade "subjetiva" e de uma ética da natureza que a Igreja irá constituir seu dogma de civilização, como a referência triunfante no ambiente social medieval. É com base em uma moralidade subjetiva e em uma ética da natureza que o Cristianismo irá articular a vida no mundo, as imposições sociais, contingentes e 
relativas, por um lado, e a verdade e os valores absolutos, por outro. Desse modo, a lei da natureza, universal, é, no homem, particular, individual, sua razão. A relativização começa quando essa razão não se põe em consonância com a própria verdade da natureza, pretendendo, talvez, encontrar verdade no nomos, isto é, em condutas que tenham sido negociadas em torno a meras convenções sociais ou, em último caso, a partir de conveniências particulares. O que seria, propriamente, um absurdo, uma "irracionalidade". No caso dos estóicos, sábio é o que logra assimilar sua vontade própria à lei natural. No caso do Cristianismo, sábio será aquele que assimilar sua razão à lei revelada.

Ora, é esse elemento de uma "lei da natureza", de uma "vontade soberana de Deus", que se traduz como "individualismo extra-mundano", o que irá permitir, bem mais tarde, a alavancagem exponencial da reforma protestante por meio da doutrina da predestinação calvinista. De que modo? Desde os primórdios e durante seu desenvolvimento medieval, o cristianismo conseguiu, por força do predomínio do holismo social da cultura greco-latina, manter o seu individualismo-fora-do-mundo equilibrado com o holismo normal da vida social. Entretanto, sempre houve uma hierarquia de valores a ser obedecida, e o individualismo sempre subordinou o holismo. Eis o que diz Dumont:

O que acontecerá na história é que o valor supremo exercerá uma pressão sobre o elemento mundano antitético que contém. Por etapas, a vida mundana será assim contaminada pelo elemento extramundano até que finalmente a heterogeneidade do mundo por completo se desvaneça. Então, todo o campo estará unificado, o holismo terá desaparecido da representação, a vida no mundo será concebida como podendo conformarse inteiramente com o valor supremo, o indivíduo-fora-do-mundo ter-se-á transformado no moderno indivíduo-no-mundo. (Dumont, 1992, p. 41)

Foi apenas com Calvino que a dicotomia hierárquica extramundo/mundo chegou ao fim. A partir de sua doutrina, o indivíduo está agora definitivamente no interior do mundo - ainda que sua alma jamais pertença ao mundo - e o valor individualista poderá, enfim, reinar sem restrições ou limitações. Embora julgando 
apenas radicalizar a posição luterana, Calvino produziu, de fato, uma doutrina diferente, cujos elementos fundamentais, intimamente associados entre si, são três:

a) Deus é vontade soberana;

b) O homem a ser salvo é eleito pela vontade soberana de Deus - teoria da predestinação;

c) A cidade cristã , o mundo, é o objeto sobre o qual incide a vontade do indivíduo eleito.

Considerando o primeiro elemento, temos que Sua vontade soberana e, sobretudo, Sua infinita majestade são idéias que servem para afastar Deus do mundo ainda mais do que Lutero já havia feito e, certamente, muito mais do que em relação ao Cristianismo primitivo. Ao mesmo tempo, isso afirma, indiretamente, o próprio homem, feito à imagem e semelhança de Deus, como vontade, muito mais do que como razão. E não é, pois, à toa que o fundamento político moderno é a vontade do indivíduo, da qual decorre toda razão moral e prática. Uma vontade que, sendo "boa", encontra-se nada mais, nada menos, como "a melhor coisa possível", segundo Kant, o que valeria inclusive como fundamento da metafísica de nossos costumes, âncora da moralidade e da racionalidade prática.

O segundo elemento nos proporciona a compreensão de que a supremacia da vontade de Deus se exprime no dogma da predestinação: a impotência do homem diante da insondável grandeza da vontade divina. Ele elege alguns para glorificá-lo no mundo e seus eleitos são identificados pela fidelidade a essa tarefa, a ser aplicada na construção da cidade cristã. E é por isso que a desigualdade real não é um problema a ser enfrentado a sério pela consciência religiosa. Isso só começa a ser um problema com as filosofias morais "laicas" que se erguem na esteira das revoluções burguesas. Mas, do mesmo modo que a religião lança a questão da desigualdade real para uma solução espiritual "no mundo futuro", as filosofias morais setecentistas e oitocentistas, incluindo Kant, lançam a questão da desigualdade real para uma solução "no futuro", não sob a forma de uma verdade revelada, mas sob a forma de uma "filosofia da história". 
Eis o que encontramos a esse respeito, num artigo de João Paulo Bachur (2006):

O núcleo político fundamental do lluminismo (Aufklärung, esclarecimento), (é) composto por um particular arranjo conceitual envolvendo individualismo, liberalismo e filosofia da história (... ) Liberalismo, no sentido sintetizado pela clássica expressão "laissez faire, laissez passer" de origem fisiocrata, não se reporta apenas e imediatamente ao mercado, mas tem em conta uma luta política contra o absolutismo. Esse liberalismo é correlato a um individualismo muito específico, obtido a partir do confronto entre impulsos egoístas e impulsos "sociais" ou "sociáveis", por assim dizer. É dessa tensão extremamente sensível que emerge o mercado liberal - e a questão da desigualdade, preço a ser pago pelo desenvolvimento e pela liberdade econômica $e$ política, tem então de ser remetida ao futuro, à utopia do progresso humano garantida pela filosofia da história. O problema posto pela desigualdade não se pode resolver no presente, para cada indivíduo isolado, mas reporta-se ao gênero humano. (...) Pautada pela fé no progresso, a filosofia da história a um só tempo obscurecia a crise e remetia sua solução para um futuro remoto, isentando de responsabilidade o individualismo liberal-burguês.

E o melhor exemplo desse arranjo estabelecido entre liberalismo, individualismo e filosofia da história são, especialmente, as proposições 4, 5 e 6 da Idéia de uma História Universal de um ponto de vista cosmopolita de Kant, o pequeno escrito de 1784, que reproduzo:

(4) o instrumento utilizado pela natureza para que a espécie humana desenvolva completamente suas determinações é o antagonismo social, a insociável sociabilidade (ungesellige Geselligkeit) que força os homens a entrar em sociedade, mas ameaça dissolvê-la a cada momento;

(5) de forma que o maior problema para a espécie humana é alcançar uma organização da sociedade civil perfeitamente justa e livre;

(6) problema este que, por ser o mais difícil, será resolvido por último pela espécie humana.

Como se vê, o próprio Kant já tinha noção de que nem mesmo seus esforços na direção de um pensamento cercado de cuidados e autoconsciente de seus limites e condições poderiam almejar a tanto. A solução desse problema, ao que parece, não competia à filosofia como tal. E é talvez nesse sentido que Rorty tenha proposto que, não sendo úteis em resolver os problemas mais candentes do homem, as pretensões 
da filosofia precisariam ser, digamos, "deflacionadas", deixando que outras tentativas, em outras áreas da cultura pudessem, talvez, avançar nisso.

De toda maneira, foram apenas os excessos da Revolução Francesa que levaram à percepção e à articulação filosófica, política e sociológica da categoria central do trinômio liberalismo-individualismo-filosofia da história, que é, seguramente, essa "insociável sociabilidade" que é propriamente o individualismo. 0 termo, como se sabe, apareceu como "expressão de abuso e saturação" no discurso de um dos mais fortes oponentes da Revolução Francesa, o arquiconservador Joseph de Maistre, que passou a empregá-lo para descrever os efeitos terríveis que acompanharam a Revolução: a subversão das hierarquias sociais estabelecidas, a dissolução de laços sociais tradicionais, em favor de uma doutrina niveladora e atomizante dos direitos naturais individuais, a qual liberava cada indivíduo para ser seu próprio árbitro moral. Nesse sentido, o individualismo, para de Maistre, não era a afirmação da dignidade pessoal, mas um pesadelo de egotismo e anarquia moral. (McClay)

Apesar disso, a fórmula clássica com que o individualismo se tornou conhecido nas ciências humanas só foi posta em circulação por Alexis de Tocqueville, um pouco depois. Tocqueville deu à metáfora de Joseph de Maistre um sentido mais sutil, ainda que não menos crítico, dizendo que individualismo era o "progressivo, consciente e sistemático abandono da esfera pública por parte dos indivíduos, desejosos de se retirar inteiramente para a dimensão privada" (Vol. 1, p. 19). Mas se esse abandono se fez sentir inicialmente de modo chocante nos momentos subseqüentes à Revolução Francesa, na verdade dizia respeito a uma tendência mais profunda e duradoura, a qual precisava ser investigada a sério.

A rigor, independente do viés específico com que se pretenda apresentá-la, a ideologia individualista dominante na Modernidade, no fundo diz respeito ao modo como a minoria de indivíduos economicamente mais fortes pode legitimar suas relações de dominação com a maioria de indivíduos mais fracos. Trata-se de uma 
definição prévia em torno ao valor que deve ter prioridade na organização das leis e das regras da vida cotidiana, e nenhum de nós tem dúvida acerca de qual é esse valor, nós que fomos aculturados na cultura moderna: é claro, esse valor é o indivíduo ou, se preferirmos, a "pessoa moral".

É inegável o importante papel que a ideologia religiosa desempenhou para a instauração completa de uma auto-interpretação predominantemente individualista, sobretudo por meio de sua difusão como ética pública, a qual foi progressivamente destranscendentalizando os princípios e regras inicialmente espirituais, até torná-los mero senso comum compartilhado. Especialmente o princípio da liberdade interior, que referimos ao início, e que foi a pedra de toque da reforma de Lutero e Calvino, inicialmente, sendo depois remodelado para ser utilizado pelas filosofias morais escocesas, por Kant e, ao mesmo tempo, pelas teorias políticas burguesas em geral, tanto a economia de Adam Smith, quanto os contratualismos de Hobbes e Locke e, inclusive, Rousseau.

Herbert Marcuse analisou corretamente o conceito de liberdade que as teorias burguesas - os individualismos liberais, em geral - assumem a partir do desenho do indivíduo como vida interior subjetiva, inicialmente como ética religiosa e privada e, em seguida, como moral laica e pública:

O indivíduo não pode ser, ao mesmo tempo, livre e não-livre, autônomo e heterônomo, sem que o ser da pessoa tenha que ser concebido como divisível, como pertencente a diferentes esferas. Isso é perfeitamente possível na medida em que a hipostasia do eu como 'substância' é posta de lado. O decisivo é como essa divisão ocorre. Ela é considerada dualisticamente, como bipartição: são introduzidas duas esferas relativamente fechadas dentro de si mesmas e a liberdade e a nãoliberdade, como totalidades, são distribuídas entre essas esferas de tal modo que uma delas é totalmente um reino da liberdade e a outra é totalmente um reino da não-liberdade. $E$, em segundo lugar, o reino da liberdade passa a ser considerado como o 'íntimo' da pessoa como membro do reino da razão ou de Deus (como 'Cristo', como 'coisa em si', como coisa inteligível), ao passo que todo o 'mundo exterior', a pessoa como membro do reino natural ou então do mundo da concupiscência caído em desgraça (como 'homem', como 'fenômeno'), é transformado em sítio de nãoliberdade. A concepção cristã do homem como 'ens creatum' 'entre' a 'natura naturans' e a 'natura naturata', com a herança fatal do pecado 
Marcuse traça seu diagnóstico no plano de uma investigação sobre os fundamentos da autoridade na vida moderna, preocupado com as regras do jogo que determinam a liberdade prática do indivíduo, sua liberdade e não-liberdade sociais. 0 mais interessante, ele observa, é o entrelaçamento peculiar que liberdade e nãoliberdade possuem, desde os escritos de Lutero sobre a liberdade do cristão, e que alcança na doutrina kantiana da liberdade sua expressão mais clara e elevada.

Para Marcuse, a relação de ambas é de fundamentação, a saber, a liberdade do cristão é a condição de sua não-liberdade. E isto ocorre de modo necessário, na medida em que a não-liberdade no mundo exterior - o que Dumont havia chamado de intramundano - é uma "eterna conseqüência" da liberdade no mundo interior - o que ele havia chamado de extramundano. Tendo sido "libertado antes de sua história real", o cristão vê essa história real - intramundana - como a "história de sua nãoliberdade". Do ponto de vista religioso protestante não poderia ser diferente, já que, a rigor, "a completa liberdade do homem também no mundo 'exterior' seria por si mesma sua completa libertação de Deus, sua escravização sob o domínio do Diabo" (Marcuse, 1981, p. 57-58). Nesse caso, não há nenhum sentido positivo para a expressão "libertação histórica do homem". Ao contrário, uma libertação deste tipo poderia significar apenas a libertação do homem de seu próprio Deus, uma liberdade para praticar o mal.

Portanto, não é de causar espanto que o valor do indivíduo como interioridade absoluta tenha alcançado o ápice que alcançou precisamente nessa conformação cultural particular: é apenas e tão-somente como indivíduo-sujeito, isto é, como ser racional único dotado de uma vida interior própria e autônoma que o homem de Lutero encontra o sentido e a saída para a sua própria existência. Se não fosse assim, ele não poderia advogar o infinito direito à liberdade de sua essência insubstituível, gerada na eternidade da mente divina. Não sendo assim, não seria 
possível suportar a contradição existente entre a liberdade infinita de pensamento e auto-referência e a submissão real às potências exteriores, que estão fundamentadas em ordens diversas, entre outras, na natureza, na história e na organização social. Ordens legítimas porque criadas ou permitidas e toleradas por Deus, em suas determinações imperscrutáveis e inquestionáveis.

Em outro lugar, defendi a tese de que o individualismo, em sua forma mais sofisticada, encontra-se vertido por meio da metáfora rortyana da "autocriação privada", que vem a ser uma forma neo-pragmatista, pós-moderna e neoliberal para as idéias mais antigas de salvação individual, vocação, subjetividade burguesa, indivíduo moral autônomo, auto-expressão romântica etc., entre outras. Mas essa metáfora só foi possível porque houve antes um número razoável de intelectuais literários, de Hobbes a Nietzsche, de Stuart Mill a Sartre, que forjaram as passagens mais persuasivas do valor do indivíduo na cultura.

Uma cultura, aliás, dominante, como afirmei ao início. Portanto, colocar-se em sua contracorrente é um esforço que precisa valer muito a pena para ser empreendido. É certo que houve também muitos intelectuais que tentaram, em especial a partir da tradição dos socialismos utópicos e dos textos de Marx e Engels, forjar uma literatura alternativa, com outras metáforas de tom e cunho pósindividualista. Mas isso, infelizmente, tentou ser feito num combate direto. Ora, devido, em parte, à enorme assimetria das forças em combate, o mero antagonismo direto não conseguiu nada além de fazer com que as oposições tradicionais simplesmente perdessem os primeiros rounds da luta sem aparente chance de recuperação.

A questão é que isto não ocorreu apenas pela inferioridade em forças diante do adversário. De fato, essa incapacidade revolucionária ocorreu em boa parte devido à origem comum na ideologia religiosa judaico-cristã, o que levou as forças de oposição ao individualismo a apropriarem em diferentes graus o mesmo vocabulário de seus contendores: 
Los grandes materialistas y escépticos del siglo XVI, la extrema izquierda de la llustración y sus herederos socialistas y comunistas justifican su filosofia "subversiva" en los mismos términos del ideal humanista. El marxismo constituye uma parte integral de tal tradición. El que Marx y Engels se consideraran a si mismos como los herederos de la llustración, de la Revolución francesa y de la filosofia idealista alemana, era algo más que uma expresíón retórica. La Libertad, la Igualdade y la Justicia son términosclave en El Capital de Marx; y no es casual que su teoria econômica este precedida (em um sentido más que cronológico) por la filosofia humanista de La Ideologia Alemana (1846) y de los Manuscritos Econômico-Filosóficos (1844), a la que a su vez completa. (Marcuse, 1971, p. 206, grifo nosso).

É exatamente por esse motivo que se faz necessário revisar com todo cuidado o vocabulário, o código cultural, em que fomos reproduzidos, de modo a não repetir o mesmo equívoco. Se mantivermos o essencial desse código, não conseguiremos elaborar metáforas efetivamente novas, isto é, capazes de produzir mudanças políticas significativas.

Assim, a luta política relevante, hoje, passa pelo plano de uma reformulação completa da autocompreensão cultural, que deve ser levada a efeito também, entre outras estratégias, por meio de redescrições vocabulares hábeis, capazes de mostrar aos indivíduos fortes do mundo o sofrimento que causam em função de estarem agarrados a uma auto-imagem social e politicamente desastrosa, e aos indivíduos fracos quanto sofrem inutilmente, por compartilhar dessa crença. Mas isso, claro, não é suficiente. Supor que sim seria um tipo de delírio semelhante àquele detectado pelo Marx da Ideologia Alemã, isto é, supor que as idéias sejam originadas "na mente de alguém", que caiam do céu, e não que sejam fruto de conflitos, lutas e embates reais pela determinação da posse, distribuição, circulação e acumulação de bens "materiais" e "simbólicos".

Portanto, se parece razoável defender a liberdade e a felicidade dos indivíduos, não é razoável esperar que uma sociedade que já optou há tanto tempo pela cultura da "auto-invenção privada" (que entende liberdade e felicidade num âmbito estritamente individual, sem maiores conexões com a comunidade em que se vive) possa incluir em sua forma de vida, com o mesmo peso e valor, outra cultura que lhe é, de fato, muito suspeita e estranha, a cultura da "invenção social solidária". 
É por esse motivo que sugiro que os interessados em promover a cultura pósindividualista devem, em primeiro lugar, livrar-se de tudo o que decorre dos códigos dominantes, inclusive nos principais vocabulários filosóficos. As pessoas ficariam surpresas com o quanto esses vocabulários são individualistas. Nesse sentido, gostaria de concluir minha breve apresentação com uma citação de Dumont:

\footnotetext{
A atividade filosófica, o exercício continuado por gerações de pensadores da indagação racional, deve ter por si própria alimentado o individualismo, porque a razão, se em princípio é universal, trabalha na prática através da pessoa particular que a exerce, e, pelo menos implicitamente, afirma a sua preeminência sobre todas as coisas. (Dumont, 1992, p. 38)
}

Talvez seja hora, mesmo, de assumirmos a tarefa de um trabalho mais da imaginação do que da "reflexão", uma imaginação posta a serviço não da felicidade do maior número, mas da felicidade de estarmos, finalmente, todos juntos, finalmente livres para nos olharmos sem medo, sem divisões, sem o insustentável peso que carregamos sozinhos, o que é, se pensarmos bem, absolutamente desnecessário e inútil.

\section{Referências Bibliográficas}

BACHUR, J. P. Individualismo, liberalismo e filosofia da história. Lua Nova, São Paulo, 66 (2006): 167-203.

BARBOSA, L. Igualdade e Meritocracia: a ética do desempenho nas sociedades modernas. $2^{\text {a }}$ ed. Rio de Janeiro: FGV, 1999.

BAUMAN, Z. O Mal-estar da Pós-modernidade. Tradução de Mauro e Cláudia M. Gama. Rio de Janeiro: Jorge Zahar, 1998.

DUMONT, L. Ensaios sobre o individualismo. Lisboa: Dom Quixote, 1992.

FOUCAULT, M. A hermenêutica do sujeito. São Paulo: Martins Fontes, 2006.

GEERTZ, C. A Interpretação das Culturas. Rio de Janeiro: Guanabara, 1989.

KANT, I. Idéia de uma história universal de um ponto de vista cosmopolita. (Trad.

Rodrigo Naves \& Ricardo R. Terra). São Paulo: Brasiliense, 1986.

KUPERMAN, D. O mal da civilização. Veredas. Ano 5, n. 49, Jan. (2000): 18-24. 
MARCUSE, H. Idéias sobre uma teoria crítica da sociedade. Rio de Janeiro: Zahar, 1981. El marxismo sovietico. Madrid: Alianza Editorial, 1971.

McCLAY, W. Individualism and Its Discontents. The Virginia Quarterly Review. Summer (2001): 391-405. Disponível em:

http://www.vqronline.org/viewmedia.php/prmMID/8194. Acesso em: 27/10/2009.

RORTY, Richard. Filosofia como política cultural. São Paulo: Martins Fontes, 2009.

SODRÉ, M. A máquina de narciso: televisão, indivíduo e poder no Brasil. 3a ed. São Paulo: Cortez, 1994.

TOCQUEVILLE, A. A Democracia na América. 2 vol. São Paulo: Martins Fontes, 2000. 